\title{
Entre las fincas y la escuelita bíblica... o policial \\ Un análisis etnográfico sobre el cuidado infantil en contextos rurales de Orán, Salta
}

Pía Leavy ${ }^{1}$

${ }_{1}$ Centro de Estudios en Nutrición y Desarrollo Infantil (CEREN) Comisión de Investigaciónes Científicas (CIC) Provincia de Buenos Aires, CONICET, La Plata, Argentina

Correo electrónico: pialeavy@gmail.com
Recibido:

14 de mayo de 2019

Aceptado:

23 de septiembre de 2019

doi: 10.34096/runa.v40i2.6254

\section{Resumen}

El artículo analiza desde una perspectiva antropológica la organización social y cultural del cuidado infantil en contextos rurales del departamento de Orán (Salta, Argentina). Dicha perspectiva teórico-metodológica recupera las investigaciones feministas sobre cuidado y los estudios sociales sobre infancia para explorar los procesos de construcción de la niñez en contextos rurales salteños, y propone pensar a niñxs como sujetos activos en la organización del cuidado. El trabajo etnográfico se realizó en sectores rurales con familias criollas y avaguaraníes de nacionalidad argentina y boliviana. Las intervenciones estatales resultan insuficientes para responder a las demandas del cuidado infantil en los contextos rurales, marcados por la informalidad laboral. Lxs niñxs asumen responsabilidades en diversas tareas de cuidado y poseen un amplio margen de autonomía. La perspectiva etnográfica nos permite comprender la amplia aceptación de la escuela policial infantil, como un espacio que permite desfamiliarizar las tareas de cuidado.

\section{Between farm and children's biblical... or police school. An ethnographic analysis on child care in Orán rural contexts (Salta, Argentina)}

\begin{abstract}
The article analyzes from an anthropological perspective the social and cultural organization of child care in rural contexts from Oran (Salta, Argentine). This methodological theoretical perspective recovers feminist's research on care and social studies on childhood, to explore the processes of childhood construction in rural contexts in Salta and proposes to think of children as active subjects in care organization. The ethnographic work was carried out in rural sectors with Creole and Ava-Guarani families, from Argentine and Bolivia.
\end{abstract}

\section{Palabras clave}

Cuidado infantil; Niñez; Etnografia; Trabajo rural; Género
Key words

Child care; Childhood; Ethnography; Rural work; Gender 
State interventions are insufficient to respond to the demands of child care in rural contexts, marked by labor informality. Children assume responsibilities in care tasks and have a greater degree of autonomy. Ethnographic perspective allows us to understand the wide acceptance of the children's police school, as a space that allows defamiliarizing child care tasks.

\section{Entre a fazenda e a creche bíblica... o policial. Uma análise etnográfica sobre o cuidado infantil em contextos rurais de Orán, Salta}

\section{Resumo}

Palavras-chave

Cuidado infantil; Criança; Etnografia; Trabalho rural; Gênero
O artigo analisa, a partir de uma perspectiva antropológica, a organização social e cultural do cuidado infantil em contextos rurais do departamento de Orán (Salta, Argentina). Essa perspectiva teórica metodológica recupera a pesquisa feminista sobre cuidados e estudos sociais sobre a infância, para explorar os processos de construção da infância em contextos rurais em Salta e propõe pensar as crianças como sujeitos ativos na organização do cuidado. O trabalho etnográfico foi realizado em setores rurais com famílias crioulas e ava-guaranis, de nacionalidade argentina e boliviana. As intervenções do Estado são insuficientes para responder às demandas de cuidado infantil em contextos rurais, marcadas pela informalidade do trabalho. As crianças assumem responsabilidades em várias tarefas de cuidado e têm um maior grau de autonomia do que em outros contextos sociais. A perspectiva etnográfica nos permite compreender a ampla aceitação da escola policial das crianças, como um espaço que permite desfamiliarizar as tarefas de cuidar da criança.

\section{Introducción}

En los últimos años, los estudios sobre cuidado infantil han adquirido un novedoso dinamismo en el campo de las ciencias sociales y humanas. Con gran influencia de la teoría y la práctica feminista, estos análisis coinciden en un argumento central: que "el cuidado" constituye un fenómeno social y que no puede ser estudiado sin trascender el acto de cuidar (Zibecchi, 2013). En este sentido, los nuevos enfoques han analizado la distribución social del cuidado infantil y proponen analizarla en el cruce de las relaciones entre el Estado, la familia, el mercado y las organizaciones comunitarias (Faur, 2014; Rodríguez Enríquez y Marzonetto, 2016). De este modo, las condiciones laborales de los adultos de la familia - y sobre todo de las madres - y las políticas sociales hacia la infancia constituyen aspectos centrales para comprender cómo se resuelven las demandas de cuidado de niñxs. Estos trabajos constituyen un aporte fundamental para visualizar la desigualdad de clase y de género que sostiene la organización del cuidado y los significados culturales en torno a la maternidad y la familia que habilitan su naturalización en el contexto argentino.

No obstante, los estudios mencionados han acotado sus análisis a los ámbitos urbanos, y dejaron de lado las modalidades que adquiere la organización del cuidado infantil en contextos rurales. Por otro lado, la infancia es abordada como mero grupo de edad, cuya especificidad solo remite a la vulnerabilidad 
inmunológica que demanda cuidados especiales durante los primeros años de vida. ${ }^{1}$ En este sentido, no se consideran los aspectos culturales ligados a la construcción social de la infancia ni los procesos de formación de alteridad social en relación con dicha etapa del ciclo vital.

El presente artículo propone entonces analizar desde una perspectiva antropológica la organización social y cultural del cuidado infantil en contextos rurales del departamento de Orán (Salta). Dicha perspectiva teórico-metodológica articula las investigaciones feministas sobre cuidado (Zelizer, 2009; Zibechi, 2013; Faur, 2014) y los estudios sociales sobre infancia (James y Prout 1990; Colangelo, 2004; Szulc, 2006, 2015), con el objetivo de pensar a lxs niñxs no solo como objetos de cuidado, sino también como sujetos activamente comprometidos con su organización. La mirada etnográfica sobre las prácticas y los discursos en torno al cuidado busca, además, explorar los procesos de construcción de la infancia en el contexto rural.

El artículo se organiza en tres partes. En una primera describimos el universo laboral del ámbito rural y las situaciones típicas encontradas que elaboran las mujeres-madres para resolver las demandas del cuidado infantil y el trabajo remunerado. En una segunda parte, analizaremos los modos en que lxs niñxs participan de la organización social y cultural del cuidado infantil, atendiendo a los diversos significados que adquiere dicha categoría. Por último, caracterizaremos los espacios institucionales y comunitarios del ámbito rural donde lxs niñxs pasan parte de su vida cotidiana y los sentidos que estas prácticas adquieren.

\section{Metodología y área de investigación}

Este artículo se enmarca en una investigación de doctorado (Leavy, 2017) realizada entre 2010 y 2015 desde una perspectiva etnográfica (Guber, 2001) en contextos rurales del departamento de Orán, Salta. Estos se ubican a pocos kilómetros de Bolivia, en una zona de fronteras geográficas, jurisdiccionales y étnicas (Hirsch, 2000; Jerez y Rabey, 2006) donde se inserta un polo agrícola económico en el cual convive el complejo agroindustrial de San Martín de Tabacal, junto con empresas de producción de hortalizas de primicia - localmente denominadas fincas - que demandan mano de obra estacional. A pesar de la integración de diversos frentes productivos, la población de Orán presentaba críticos indicadores sociales ${ }^{2}$ al momento de esta investigación y más del 30\% de los hogares no poseían agua potable ni estaban conectados al sistema cloacal (INDEC, 2010). La población de los espacios rurales del contexto de Orán revelaba una amplia heterogeneidad étnica: familias kollas, wichís y ava-guaraníes principalmente, junto con familias criollas, de nacionalidad boliviana y argentina. Todas ellas pertenecían a sectores sociales pobres, con bajo nivel educativo - en su mayoría, primario incompleto-, y vivían en condiciones laborales y habitacionales inestables.

Las fincas definían el ordenamiento de la población rural, ya que poseían las tecnologías adecuadas para el uso intensivo del suelo, del capital y de la mano de obra (Rodríguez García, 2012). Según los registros del Programa de Atención Primaria de la Salud de la provincia de Salta (PROAPS), ${ }^{3}$ en 2012, en el área operativa rural residían de modo permanente 5349 personas, y entre los meses de abril y noviembre la población ascendía a 7000 u 8000 personas, aproximadamente.
1. El hecho de que la especie humana tenga crías que nacen a los nueve meses luego de la fecundación, la ubica como la "prole más frágil y dependiente de todos los mamíferos" (Hernando, 2008, p. 66). Entre la concepción y los primeros cinco años de vida se forman del 85 al $90 \%$ de las funciones del sistema nervioso central. La perspectiva biomédica y epidemiológica plantea que, en este período, el sistema inmunológico del niño madura más rápidamente, y al mismo tiempo se halla en un estado de mayor vulnerabilidad frente a los agentes causantes de enfermedades infecciosas (Gilardon, E., Calvo, E., Duran, P., Longo, E., \& Mazza, C., 2009).

2. Según el INDEC (2010), el 30,9 \% de la población de Orán presenta Necesidades Básicas Insatisfechas, valor que supera la media provincial $(14,9 \%)$ y la media nacional (9\%).

3. El Programa de Atención Primaria de la Salud se desarrolla en Argentina desde principios de la década de 1980 y comprende la asistencia sanitaria esencial y accesible a toda la población sin cobertura privada, que constituye el primer contacto entre la comunidad y los servicios de salud. Las principales actividades desarrolladas incluyen la educación para la salud, la prevención y control de enfermedades, la promoción para la salud y el suministro de medicamentos e inmunizaciones. Para profundizar, ver Torres Aliaga y Torres Secchi (2010). 
4. La Ley 26.160 es el marco jurídico que dio lugar a la implementación del Programa de Relevamiento Territorial (RETECI), que constituye un relevamiento de las tierras que ocupan y usan las comunidades, pero aún no existe un marco normativo que efectivice la titulación del territorio comunitario a nivel nacional.
En este artículo analizaremos los resultados de lo observado en una muestra de 50 familias, tomada en dos sectores rurales a los que denominamos "El 26" y la comunidad ava-guaraní "Arcoíris". Entendemos por familia a un grupo de personas que posee un "sustrato biológico ligado a la sexualidad y a la procreación que se incluye en una red más amplia de relaciones de parentesco, que a veces implican obligaciones y derechos guiadas por reglas y pautas sociales establecidas" (Jelin 1984, p. 15). El abordaje etnográfico permite entender a las familias no como una "cosa" sino como un "proceso" flexible y dinámico, que implica una "vasta gama de relaciones de cuidado y transacciones económicas" (Zelizer, 2009, p. 85).

"El 26" estaba formado por familias que vivían dentro y fuera de los terrenos finqueros. Los habitantes de este sector trabajaban en las fincas de producción agrícola o se dedicaban al "bagalleo", que consistía en el pasaje de mercaderías de Bolivia hacia Argentina por caminos internos, evitando los controles de la aduana y gendarmería. Las familias de este asentamiento eran ava-guaraníes y criollas, de nacionalidad argentina y boliviana. En este sector seleccionamos una muestra de 42 familias, 32 de las cuales habitan en fincas y 10 en el asentamiento (94 mujeres y 133 hombres). Todas estas personas eran destinatarias de las acciones del PROAPS, que tenía un Centro de Atención Primaria de la Salud (CAPS) en el asentamiento. Ninguna de ellas poseía títulos de tierra, ni contaban en sus hogares con conexión a la red de agua potable.

La comunidad ava-guaraní de Arcoíris funcionaba como una unidad de producción agrícola de pequeña escala y estaba integrada por familias ava-guaraníes de nacionalidad argentina que vivían a pocos kilómetros del centro urbano de Orán. Sus tierras habían sido inscriptas ${ }^{4}$ en el Registro Nacional de Comunidades Indígenas (RENACI-Ley Nacional 26.160), aunque eran objeto de intrusiones de terceros y de amenazas de desalojo (Comunidad Indígena Ava-Guaraní Tabacal La Loma y Etchegorry et al., 2013; Leavy, 2018). La integraban 265 personas, para quienes la producción agrícola a pequeña escala constituía su principal ingreso. Sin embargo, muy pocos podían vivir en las tierras comunitarias debido a la falta de servicios. La muestra estuvo conformada por ocho familias (22 mujeres y 19 hombres, de los cuales 15 eran menores de 10 años) que vivían permanentemente en la comunidad.

Estas muestras son el producto del "proceso de bola de nieve" (Patton, 2009) y no nos posibilitan proyectar fenómenos sociales a poblaciones generales. Los datos que se presentan a continuación reproducen la fotografía de la información recabada al momento de realizar el trabajo de campo. Se repone la foto con la finalidad de describir y contextualizar; se advierte que se utilizan seudónimos con el objetivo de preservar la identidad de los interlocutores informantes clave o entrevistados - y de los sectores específicos que habitaban.

\section{Malabares rurales}

\section{Hacer crecer la cría}

“Desde siempre trabajé en el campo, pasé por todas las fincas, juntaba agua de los charcos, éramos hermanas de las ratas (risas) dormíamos en el piso, jtrabajé en cada finca! (risas) pero lo que más trabajo da es hacer crecer la cría, hacerlos crecer [...] nosotros somos los que los traemos al mundo y ellos no saben hacer nada y ahí nos tenemos que encargar, y si no se encarga una, no se encarga nadie, el cuidado de los changos no se termina nunca...". (Entrevista Rosa, madre criolla, Orán, Marzo 2011) 
Históricamente, en el contexto de las sociedades occidentales, se han definido como femeninas las actividades "reproductivas" que se realizan al interior del hogar, y como masculinas aquellas actividades "productivas" que generan un ingreso económico. De este modo, lo que se realiza afuera del hogar ha sido entendido como trabajo, mientras que lo que se realiza puertas adentro se corresponde con el cuidado, y las mujeres estarían naturalmente capacitadas para realizarlo de modo altruista. Ahora bien, esta división sexual del trabajo no coincide con lo observado en las familias de Orán - al igual que en otros contextos - donde las mujeres realizan tareas productivas dentro y fuera de su hogar. Rosa era una de ellas, quien señalaba que el cuidado de los changos (niña/ os) es el trabajo de hacer crecer la cría, que se diferencia del trabajo en el campo (las fincas) porque no se termina nunca. Hacer crecer la cría implica alimentar, hacer dormir, vestir, comprar comida - planificarla, prepararla, cocinarla y servirla-, limpiar el hogar y lavar ropa, entre otras varias acciones cotidianas que posibilitan la reproducción de los miembros de la familia. Veremos más adelante que también incluye tomar decisiones sobre aquello que se considera que es lo mejor para sus hijxs.

Podemos decir que este trabajo no se termina nunca en la vida de una mujer, sobre todo si pertenece a la clase social de Rosa, que había aprendido las tareas de cuidado desde niña y las continuaba realizando como madre y como abuela. Todas las mujeres contactadas habían trabajado en el campo antes de ser madres y durante sus embarazos. Ninguna de ellas había percibido una licencia por maternidad. Estaba completamente naturalizado que los embarazos implicasen "dejar de trabajar en el campo", es decir, de modo remunerado. Esto coincide con los datos que arrojó nuestra muestra: de las 50 familias seleccionadas, en 46 de ellas, el principal sostén del hogar (PSH) trabajaba en fincas de producción agrícola. De esta porción, solo dos lo hacían como "efectivos" y eran varones. La categoría nativa de "efectivo" implicaba una relación laboral más estable que la de los "jornaleros", que cobraban una remuneración por día, pero más adelante observaremos que no necesariamente esto significaba una relación laboral como lo indica el trabajo registrado. ${ }^{5}$

En Argentina, la informalidad laboral tiene efectos determinantes sobre el cuidado infantil, pues las intervenciones estatales en torno a este se limitan a dos esferas: la protección a la madre trabajadora en el régimen laboral (durante el período de gestación, alumbramiento y lactancia), y la obligatoriedad de la educación básica, que constituye la principal estrategia del cuidado para las familias (Rodríguez Enríquez, 2005). Asimismo, la escuela pública tiene una muy alta presencia en la sala de cinco años - cerca de la universalizaciónpero disminuye fuertemente en las salas de 4 y 3 años (IIPE, 2002; DINECE, 2007 y 2010 en Zibecchi, 2013, p. 431). Esto mismo hemos observado en el contexto de Orán. En esta localidad, las escuelas analizadas en el ámbito rural ofrecían matrícula de inscripción a partir de los 5 años, por lo tanto, el cuidado de niñxs desde su nacimiento hasta dicha edad recaía exclusivamente sobre las mujeres de las familias.

La Asignación Universal por Hijo (AUH) y por Embarazo es una de las principales estrategias estatales implementadas con el objetivo de revertir las desigualdades generadas por la informalidad laboral. Esta consiste en una transferencia monetaria a lxs hijxs de personas desocupadas que trabajan en el mercado informal o que ganan menos del salario mínimo, vital y móvil. ${ }^{6} \mathrm{Si}$ bien esta intervención constituye un avance en materia de protección social, refuerza el maternalismo político (Nari, 2004), pues otorga derechos sociales a las mujeres solo por su condición de madres. Existían otras intervenciones
5. El "trabajo registrado" implica: cobertura de aseguradora de riesgos del trabajo, un seguro de desempleo, los beneficios del acuerdo colectivo de trabajo (viáticos, refrigerios, escalafón, antigüedad, ropa de trabajo), aportes jubilatorios, licencias por maternidad/paternidad, vacaciones pagas, aguinaldo, seguro de vida y una pensión para la familia en caso de fallecimiento (INTI, 2017).

6. En la actualidad, el monto de la Asignación por Hijo y por Embarazo es de 2.652 pesos argentinos. El $80 \%$ de esta cifra se cobra por mes y el $20 \%$ restante se cobra a fin de año con la presentación de la Libreta de Asignación Universal, que da cuenta de que el niñx ha cumplido con la asistencia escolar y los controles sanitarios. Recuperado de: https://www.anses. gob.ar/informacion/montos-deasignacion-universal-por-hijo-ypor-embarazo-para-proteccionsocial (Consultado el 19/9/2019). 
7. Rosa refiere al subsidio por más de siete hijos declarado por el Decreto 2360/90. "Está dirigida a aquellas madres de 70 más hijos en estado de vulnerabilidad social que se encuentren sin amparo previsional o no contributivo, no posean bienes, ingresos ni recursos que permitan su subsistencia y que no tengan parientes obligados legalmente a proporción". Recuperado de: http://www.desarrollosocial.gob. ar/wp-content/uploads/2015/07/ Decreto-2360-1990-Reglamentacion-de-la-Ley-de-pensionesa-madres-de-7-o-m--s-hijos. pdf (Consultado el 4/7/2017). estatales hacia la población materno-infantil, como las acciones sanitarias del PROAPS y el Plan Nacional de Seguridad Alimentaria, pero estas se focalizaban en determinadas familias y niñxs que estuviesen atravesando situaciones de vulnerabilidad específicas (Leavy, 2015; Leavy, Szulc y Anzelin, 2018).

La mayoría de mujeres con hijos recién nacidos apelaba a sus redes familiares para poder continuar el trabajo en las fincas. Tal era el caso de la familia Ruiz, en que la abuela Norma (52) quedaba a cargo de sus nieto/as Claudio (12), María (10), Crespín (9), Silvia (7) y Rita (5), mientras su hija Carolina (35) y su yerno Justo (35) salían a trabajar a las fincas como jornaleros. En relación con este trabajo, Carolina explicaba que "el capataz te explica cuando hay tarea" (Registro de campo, jornalera rural criolla, Orán, septiembre 2012), lo cual señala la inseguridad de la relación laboral y la inestabilidad del ingreso económico. Tal como en otros hogares, el único ingreso fijo de esta familia estaba constituido por la AUH.

Distinto era el caso de las familias en las que el principal sostén del hogar trabajaba como "encargado efectivo" de la finca. Esta relación laboral no necesariamente implicaba un trabajo registrado como lo indica la Ley № 26.727 de Régimen de Trabajo Agrario (Egan, 2013), pues hemos observado en sus recibos de sueldo que la patronal no estaba aportando las cargas sociales correspondientes. Sin embargo, los encargados tenían una relación más estable con los dueños de las fincas y podían acceder a viviendas alejados de los "conventillos", que estaban superpoblados de familias de jornaleros. Tal era el caso de lxs Vélez, que vivían en cuatro viviendas ubicadas en la entrada de una finca. Allí, Rosa Vélez (47), mujer de Elías (52) y madre de once hijxs, había organizado un local de venta de comidas (pensión) para los empleados rurales de la finca. De este modo, cuando Rosa cocinaba para sus familiares, también lo hacía para sus clientes e incluso cuidaba de los hijos de su hija Romina (25), Natanael (4) y Lionel (1), todo al mismo tiempo. Respecto de esta actividad, Rosa me explicaba:

como Elías es efectivo nosotros no cobramos asignación, yo sólo cobro el subsidio de los hijos ${ }^{7}$ y no me alcanza para mis cosas y cuesta sacarle a mi patrón, nunca me da y yo nunca tengo para mí, pero con la pensión hago unos pesitos y le puedo dar a mis hijos. (Entrevista Rosa, criolla, Orán, Marzo 2011).

Rosa se refiere a su marido como su patrón, y no está refiriendo a cualquier relación laboral, sino a los modos en que son comprendidas las experiencias de trabajo en este contexto, signadas por la informalidad. El caso de Rosa, como el de muchas otras mujeres en Orán, permite observar que las mujeres no acceden a los salarios del principal sostén del hogar. Asimismo, Rosa señala que ella es la única que les pasa dinero a sus hijxs, con lo cual advierte tensiones en su relación de pareja.

Estas situaciones permiten observar que el cuidado lejos está de ser una actividad únicamente privada y/o individual. Parafraseando a Faur (2014), las mujeres de Orán se constituían en malabaristas rurales, pues pasaban sus días resolviendo las tensiones entre el cuidado familiar cotidiano, los servicios públicos (escuela, salud, transporte), que no siempre eran funcionales a las necesidades de sus hogares y a las obligaciones del mercado. Tal era el caso de Carina (22), que decidió mudarse a la comunidad Arcoíris con su pareja, Marcos (20), cuando quedó embarazada, porque allí podía dejar a su beba y a su hijo de tres años al cuidado de familiares de él. En este sentido, Carina explicaba: "aquí los changos pueden estar con nosotros mientras trabajamos la tierra, 
en las fincas hay que trabajar campo adentro y no pueden estar" (Entrevista Carina, madre ava-guaraní, octubre 2014). En la comunidad, cada familia poseía una parcela donde principalmente se producían bananas para vender en la feria franca de Orán, pero también había espacios destinados a la producción para consumo propio. Si bien los habitantes de Arcoíris eran lxs únicxs habitantes del ámbito rural que tenían un reconocimiento estatal del derecho a sus tierras, la falta de vehículos propios para llegar hasta la ruta y de un transporte público adecuado obstaculizaba el acceso a las escuelas que se ubicaban en la ciudad de Orán. Por estos motivos, la vida en la comunidad solo era posible para familias que no tuviesen hijxs en edad escolar.

En otros casos, las familias seguían un modelo transnacional (Ariza, 2000) para responder a las demandas del mercado y el cuidado infantil. Tal era el caso de Estela (22), oriunda de Chuquisaca (Bolivia), que había migrado con su pareja y su beba de siete meses a trabajar como jornalera a una finca de Orán, pero dejaba a sus hijxs mayores de seis y cuatro años con su mamá, en la ciudad boliviana de Tarija. "Ella es pequeña y me permite trabajar", me decía refiriéndose a su hija bebé (Registro de campo, Estela, madre boliviana criolla, mayo 2011). Así pues, ella utilizaba un aguayo ${ }^{8}$ con el que sujetaba a su hija en la espalda para poder trabajar en la cosecha manual. Cuando iba creciendo, comenzaba a realizar otras actividades rentadas, como elaborar comidas para vender a los empleados rurales o pedirle al encargado de la finca que le asignara tareas que pudiera realizar en su casa. Como por ejemplo, "el tutorado", que consistía en cortar juncos de mimbre para luego sostener las ramas de tomate; esta era una actividad rentada que realizaban mayormente las mujeres porque no implicaba trabajar campo adentro.

El concepto de familias transnacionales fue elaborado para comprender las configuraciones familiares que surgen de las migraciones (Cerruti y Maguid, 2010) y permite observar que no hay nada "natural" en el modo en que las mujeres experimentan la maternidad. Estas familias se define como aquella cuyos miembros viven gran parte del tiempo distanciados unxs de lxs otrxs, y que son capaces de crear vínculos que permiten que estos se sientan parte de una unidad y perciban su bienestar desde una dimensión colectiva, a pesar de la distancia física (Bryceson y Vuorela, 2002). Asimismo, esta dimensión colectiva podemos pensarla siguiendo el planteo de Gago (2014) en torno a la fuerza laboral migrante boliviana, que viaja reformulando un capital comunitario, capaz de funcionar como "recurso de autogestión, movilización e insubordinación, pero también como recursos de servidumbre, sometimiento y explotación" (Gago, 2014, p. 25), que se articula con la voluntad de progreso y de inversión de sí.

También encontramos mujeres que hacían arreglos con los patrones para realizar tareas domésticas y de cuidado infantil de modo remunerado. Tal era el caso de Clara Marylin (24), criolla de origen argentino que vivía con sus hijos Ricardo (9), Luis (7) y Dilma (5) porque su marido Héctor "cayó preso" luego de "terminar a los machetazos en un bar" (Entrevista Clara, madre criolla argentina, marzo 2011). Clara no podía trabajar en la cosecha porque nunca había podido hacer el reposo correspondiente luego del nacimiento de sus hijxs por cesárea. Así pues, cuando su marido dejó de trabajar en la finca, ella le dijo al patrón: "no tengo adónde ir, que puedo hacer la limpieza y que además puedo cuidar a otros niños, así otras madres trabajan... Y ahí nomás me dijo que podíamos quedarnos" (Entrevista Clara, madre criolla argentina, marzo 2011). Tal como explica Zibecchi (2013), en los sectores más pobres, las estrategias de cuidado pueden ser también estrategias de supervivencia. En el caso de Clara, ofrecerse como
8. El aguayo tradicional es un tejido hecho a mano utilizado por las mujeres del altiplano de Bolivia y Perú. En la actualidad pueden estar confeccionados de modo industrial, de todos modos, es una tela muy resistente, que puede utilizarse para cargar bebés en la espalda o para transportar los efectos personales o las mercancías. 
cuidadora le permitía obtener un ingreso económico frente a la falta de redes familiares, el encarcelamiento de su pareja y su condición de salud producto de no poder acceder a licencias por maternidad.

Las situaciones observadas configuran escenas características de un "neoliberalismo desde abajo" de acuerdo con el cual las mujeres autogestionan políticas de cuidado, "subsanando las actividades y los servicios de reproducción que no existen" (Gago, 2014, p. 24). Estos casos también permiten observar que el mandato de género social y cultural es asumido de distinto modo por las mujeres. En un contexto de profunda inestabilidad laboral, estas racionalizan tiempo y tareas para responder a las tensiones entre trabajo y familia. Así pues, resulta equivocada la idea de que las actividades de reproducción de las mujeres y lxs niñxs - veremos más adelante- no tengan importancia en la economía general de los hogares (Zelizer, 2009).

\section{Haciendo de madre y cuidando de todos}

Lisbele Colque (26) era otra de las mujeres que había organizado un comercio en el interior de su casa. Allí vivía con su pareja, Diego (28) - ambos, criollos de origen boliviano-, con sus hijos, Andrés (10), Juan (5), Catalina (3) y Raquel (1). Además, vivía temporalmente con ellos, Lucas (12), un sobrino cuyo padre estaba trabajando en una finca en Jujuy. Mientras Andrés y Juan iban a la escuela en el turno tarde, las niñas se quedaban en el hogar al cuidado de Lisbele. Si bien su casa solo contaba con dos cuartos y un patio con alero, ella usaba un armario como mostrador de golosinas y bebidas con el cual había armado un quiosco. En una oportunidad, visité su casa cuando ella había llevado a Raquel al pediatra y el resto de los hijos se quedaron en la casa. "Yo soy el que está a cargo", me dijo Andrés, y me invitó a pasar.

Lucas y Andrés habían quedado a cargo del quiosco, que Juan estaba desesperado por atender "si viene alguien a comprar lo quiero atender yo, por favor, por favor", exclamaba a los gritos el pequeño Juan. Lucas estaba muy serio y le decía, "eres muy chango todavía, las golosinas las vendemos nosotros", ubicándose en un rango de responsabilidad mayor por su edad. Encargarse de la venta de la del quiosco era un trabajo de adultos, que Lucas y Andrés deseaban realizar y mostrarme. Mientras esperaban que se acercara algún cliente, Andrés observó que su hermana se sentó en el piso y le dijo en voz alta: "Catalina ino!, en el piso te sientas con una manta". Fue al cuarto a buscar una manta para que la niña no se sentara en el piso de tierra y luego me explicó:

Andrés: - es que sino después lleva tierra a todos lados, además acá hay víboras, yo tengo el machete por cualquier problema, por si se quiere meter con mis hermanas. Pía: - ¿En serio? No te creo. ¿Te parece que vas a cazar una víbora con un machete? Mirá que las víboras son rápidas.

A: - Sí, pero mi padre me ha enseñado, yo sé cazarlas y así yo puedo cuidar de todos. Y ahí nomás Andrés fue caminando hasta su cuarto y trajo el machete que tenía debajo de su cama (Registro de campo, Andrés, niño El 26, mayo 2011).

En esta situación de campo podemos observar que yo hablaba con Andrés desde mis propias construcciones de infancia, sin tomar con seriedad lo que decía mi interlocutor. Para mis parámetros de "infancia normal", si un nene me dice que tiene un machete, pienso que debe ser de juguete; que no va a tener acceso a un arma blanca. No obstante, Andrés se estaba refiriendo a un machete verdadero, con mango de madera y filo de metal, que su papá le había enseñado a usar en caso de cruzarse con una víbora. No vamos a argumentar 
aquí si es correcto o no que un niño de 12 años tenga un machete debajo de su cama, lo que nos interesa señalar es que en estos contextos, no podemos pensar a la infancia desde el sentido común occidental, que la comprende como un conjunto de individuos aún no integrados a la vida social, definidos "como carentes de autonomía, responsabilidad por sus actos, ciertas facultades cognitivas y capacidad de acción social" (Szulc, 2006, p. 27). Ser niña y/o niño en estos contextos sociales implica tener un mayor grado de autonomía que en sectores de clase media urbana y asumir responsabilidades que pueden ser vistas como riesgosas desde otros parámetros culturales.

Así pues, en una oportunidad que visité la casa de la familia Ruiz y no estaba la abuela Norma, me encontré con María (10) armando un fuego con sus dos hermanas menores, Silvia (7) y Rita (5). María estaba abanicando con un cartón las pequeñas llamas para que prendiera la madera, mientras las dos hermanas estaban mirando televisión. "Norma se fue a comprar comida y mis hermanos salieron a lo de Matilda - vecina de comunidad ava-guaraní- ellos salen y yo me quedo aquí haciendo de madre" (Registro de campo, María niña El 26, mayo 2011). María, con sus diez años, estaba a cargo de alimentar a las gallinas y cuidar a los pollitos, y también realizaba distintas tareas domésticas, como barrer, lavar ropa, pelar papas, ir a hacer mandados y quedarse al cuidado de sus hermanas más pequeñas.

En los significados que adquieren las tareas de cuidado para María y Andrés, podemos observar los modos en que las desigualdades de género se experimentan en la más temprana infancia. Si bien Andrés realiza tareas "femeninas" de cuidado, como cuidar que su hermana pequeña no se llenase de tierra los pies, el cuidado de todos que expresa refiere a la protección de agentes intrusos y a la defensa de peligros externos. Esta forma de cuidar se articula con los mandatos de género de los varones: ser valientes, corajudos, y tener fuerza física para pelear contra posibles intrusos. Es otra forma de cuidar, que significa defender y mostrar ser competentemente varón (Connell, 1997). Para María, hacer de madre implicaba asumir tareas reproductivas del hogar: hacer el fuego para preparar la comida y cuidar que las dos hermanas más pequeñas no se acercaran al fuego ni se fueran de la casa.

Estas situaciones etnográficas permiten observar que lxs niñxs no solo son consumidores u objetos de cuidado en el interior del hogar. Ellxs participan activamente tanto en tareas de cuidado como en actividades productivas. En este sentido, la participación en estas últimas no solo es un recurso didáctico" señala Zelizer (2009, p. 263). Lucas y Andrés estaban atendiendo la pensión, escuchaban al cliente, recibían el monto del precio de los productos y daban cambio. No estaban "jugando", estaban participando de actividades productivas del hogar, mientras cuidaban de los hermanos menores.

Estas escenas nos permiten observar también el rol activo de lxs niñxs en la responsabilidad del cuidado de lxs más pequeñxs. Tanto María, como Andrés y/o Ricardo (el hijo de Clara) estaban a cargo de sus hermanxs menores en el viaje a la escuela, que quedaba a más de 10 kilómetros. El viaje implicaba esperar el colectivo en la ruta y compartirlo con los trabajadores bagalleros y jornaleros.

La autonomía de lxs niñxs del ámbito rural se traduce en una mayor capacidad de decisión y en la circulación permanente por diversos espacios, privados y públicos. Lxs niñxs circulan sin compañía de adultxs, caminando y/o corriendo por cultivos, terrenos de fincas y las viviendas de sus vecinos. Diversas 
9. El concepto de "experiencias formativas" proviene del campo de la antropología de la educación, donde se ha incorporado "la idea de apropiación como contrapeso al concepto de socialización, desarrollando la noción de experiencia formativa en referencia al conjunto de relaciones y prácticas cotidianas (escolares, familiares, barriales, etc.) en las que los niños y niñas se involucran activamente y que condicionan, en tanto limitan o posibilitan, el sentido de sus diferentes construcciones" (Rockwell, 1995 y Achilli, 1996 en García Palacios, 2015, p. 53). investigaciones (Hecht, 2010; Colangelo, 2009 en García Palacios, 2015, p. 51) sugieren que esta autonomía infantil no debe ser observada como una "falta de cuidado" sino como la presencia de un fuerte andamiaje grupal y familiar que les da tanto libertad como seguridad de movimientos. Ahora bien, tal como hemos observado, este andamiaje puede ser útil para lxs niñxs que ya saben caminar, pero en la mayoría de casos, no lograba resolver las demandas de cuidado en los primeros años de vida.

Respecto de la autonomía infantil, Antonella Tassinari (2007) sostiene que, en las comunidades indígenas, esta forma parte de una "pedagogía nativa" que habilita a lxs niñxs a circular por diversos espacios para "verlo todo" y reconocer su agencia en el aprendizaje. Consideramos que estas ideas pueden pensarse también para lxs niñxs conocidos durante la labor etnográfica, quienes, al poder "verlo todo", pueden participar de diversos espacios de los lugares donde viven, "circulando" por diversas experiencias formativas ${ }^{9}$ (García Palacios, 2015, p. 53). Así pues, en los próximos apartados, indagaremos en otros espacios institucionales - fuera del ámbito familiar - por donde lxs niñxs de Orán circulan y pasan parte del día.

\section{Las escuelitas de Orán}

Lxs niñxs contactadxs durante el trabajo de campo en Orán de entre 5 y 12 años asistían a escuelas públicas situadas en el ámbito rural. Aún con la limitación de la falta de matrícula en las salas de tres y cuatro años, las dos escuelas primarias observadas ofrecían un espacio de cuidado por fuera del ámbito doméstico, al que lxs niñxs asistían diariamente y donde además se alimentaban. Según el turno, lxs estudiantes desayunaban o merendaban en dicha institución. De este modo, la obligatoriedad de la educación básica constituía la principal intervención estatal en materia de cuidado infantil para estas familias contactadas.

El trabajo etnográfico nos permitió conocer otros espacios institucionales, que también recibían el nombre de escuelas pero que funcionaban por fuera del horario de la escuela primaria y que permitían desfamiliarizar las tareas de cuidado infantil. Una de ellas era localmente conocida como la "escuelita policial". Esta actividad dependía de la Dirección de Prevención y Orientación Comunitaria de la policía salteña y funcionaba en todas las dependencias policiales de la provincia. Para inscribirse, los padres presentaban el documento de niñas/os de entre 6 y 13 años, donde debía figurar la dirección postal para certificar que los alumnos concurriesen con sus vecinos.

Lxs niñxs de El 26 tenían la sede de la escuelita policial en el destacamento policial de Aguas Blancas, al que iban tres veces por semana: martes, jueves y sábados, a contraturno del horario escolar. Allí lxs alumnxs eran recibidos y entraban corriendo al patio. Una vez que iba llegando la totalidad del alumnado, las niñas pasaban a un salón en el que cursaban su clase de gimnasia y los niños iban a su clase de fútbol. Los profesores varones usaban uniformes de policía, y las profesoras mujeres tenían delantal blanco y no siempre pertenecían al cuerpo policial. Mientras las nenas pasaban a otro salón donde iban a su clase, una de estas les decía: "recuerden que las niñas se atan el pelo con colita alta antes de entrar" (Registro de campo, escuelita policial, Orán, octubre 2015). Estas escenas permiten observar cómo en este espacio institucional también se construyen las desigualdades de género entre niños y niñas (Morgade, 2001). 
Más allá de estas cuestiones, la escuelita organizaba una especie de club de recreación infantil. Allí se brindaban actividades de orientación cultural, artística y tradicional (folclore, canto, artesanías, música, dibujos), cuyos trabajos y habilidades se exhibían en "exposiciones, exhibiciones, tendederos, encuentros de banda de música, danzas y festivales folclóricos" ${ }^{10}$ Por otro lado, y no menos importante, brindaba a niños y niñas una "copa de leche", lo cual brinda un alivio a las familias en relación a la alimentación de los niños. Además, para quienes asistían, la escuelita policial constituía la posibilidad de irse de campamento y conocer diversos lugares de la provincia. En este sentido, Natanael (6), el nieto de Rosa Vélez, que asistía a la sede en Aguas Blancas, me contaba:

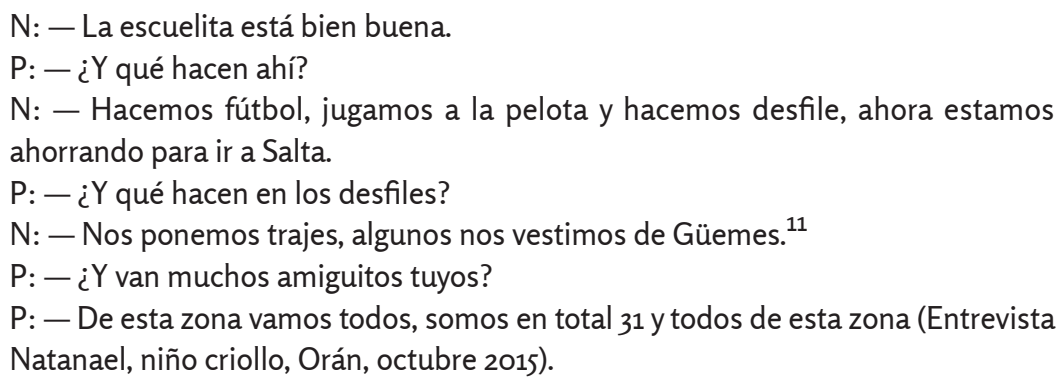

Por zona, Natanael se refería a la zona de fincas entre El 26 y Aguas Blancas. De El 26 exclusivamente iban solo tres niñxs, ninguno de ellos perteneciente a la comunidad ava-guaraní. No podemos afirmar que no asistan a la escuelita policial niñxs indígenas. Sin embargo, no podemos dejar de mencionar que los valores promulgados en dicha institución se articulan con el relato identitario provincial, que "moraliza un conjunto de identidades y diferencias colectivas" (Lanusse y Lazzari, 2008, p. 186). Según este relato, la salteñidad hegemónica se compone por las identidades "de lo gaucho, lo criollo e hispanizante, mientras que los otros, que han sido expulsados de la historia y del nosotros, son los collas e indios del Chaco" (Lanusse y Lazzari, 2008, p. 193, énfasis de los autores). La figura de Güemes y su poncho de colores rojo y negro, que visten la bandera de Salta y los alumnos que desfilan, representan los valores de la patria y su defensa, así como también el borramiento de las diferencias indígenas. En este sentido, Güemes constituye una figura central en la construcción de la identidad hegemónica salteña y de los valores de la patria, que la escuelita policial propone inculcar a los jóvenes del mañana, sus futuros defensores. (Gobierno de la Provincia de Salta, 2 de octubre de 2014).

“Acá está el Nata(nael), en los desfiles de la escuelita, con su gorra bien puesta de policía", me mostraba en una fotografía su mamá, Romina, orgullosa. Para las madres como ella, la escuelita además tenía una valoración positiva, pues implicaba la posibilidad de proveer a su hijo una formación en valores adecuados:

R: - Yo lo mando para que se porte bien, para que haga cosas de nene normal.

$\mathrm{P}:-i Y$ qué es un nene normal?

R: - Que juegue, que respete, que no esté con flojera (vagancia) acá todo el día. Porque se quedan acá, y no hacen nada y puede salir machado (alcohólico). Así que va ahí, los martes y jueves y sábados. Organizan desfiles, hacen gimnasia. Y se portan bien. (Entrevista Romina, madre criolla Orán, octubre 2015)
10. Sitio Web Gobierno de la Provincia de Salta (10/4/2014). Inscripciones abiertas para Los Cuerpos Infantiles de Policías. Recuperado de: http://www.salta.gov.ar/prensa/ noticias/inscripciones-abiertas-para-los-cuerpos-infantiles-de-la-policia/29946 (Consultado en 5/6/2017).

11. Martín Miguel de Güemes (Salta, 1785-1821). Militar y patriota argentino. Gobernador de Salta desde 1815 , organizó las partidas guerrilleras que impidieron el avance del ejército español en el Alto Perú, lo que permitió a San Martín la preparación del ejército de los Andes. Para profundizar en los significados que implica Güemes en la cultura salteña, ver Lanusse y Lazzari (2008). 
12. En el año 2014 funcionaban 199 cuerpos infantiles en toda la provincial a los que acudían 7622 niños. Gobierno de la Provincia de Salta. (10/4/2014). Inscripciones abiertas para Los Cuerpos Infantiles de Policías. Recuperado de: http://www.salta.gov.ar/prensa/ noticias/inscripciones-abiertas-para-los-cuerpos-infantiles-de-la-policia/29946 (Consultado 5/6/2017).

13. La Unión de las Asambleas de Dios fue fundada por la canadiense Alice Wood, que llegó a Argentina en 1910 y permaneció unos años en Gualeguaychú (Entre Ríos), para radicarse luego en la localidad de 25 de Mayo (provincia de Buenos Aires), donde fundaría la primera congregación de la Unión de las Asambleas de Dios en el país. Para ver más sobre Evangelio y pentecostalismo en estos contextos, recomendamos César Ceriani Cernadas (2011).
La idea de infancia "normal" se relaciona con la definición hegemónica de infancia, que prescribe que lxs niñxs crecen y se desarrollan en el ámbito doméstico familiar, donde deben jugar todo el día, y en la escuela, donde deben aprender (Szulc, 2006). Es interesante observar que, si bien en el contexto de Orán hemos conocido experiencias de infancia heterogéneas, la idea de infancia "normal" guía el horizonte de aspiraciones y de valores de las personas de estos contextos, quienes también están atravesados por una idea hegemónica de infancia, que procuran para sus hijxs. En este sentido, para Romina, la vagancia y el alcohol constituyen peligros latentes que debe evitar para el futuro de su hijo.

El cuidado infantil también constituye una vía de acceso privilegiada para explorar los vínculos intergeneracionales y los valores que guían las decisiones que toman lxs adultxs. En este sentido, Norma Ruiz, que nunca había asistido a la escuela, explicaba que para ella lo más importante era que sus nietxs "terminen la escuela y no sean bagalleros" (Entrevista, abuela criolla, Orán, marzo 2011). Por su parte, Haydeé, abuela ava-guaraní de Arcoíris, sostenía que era importante que aprendieran el cuidado de las plantas, "porque crecen en las ciudades y no saben cuidar la tierra ni cómo hacer crecer los cultivos y esos conocimientos son importantes para la vida" (Entrevista Haydeé, Comunidad avaguaraní, Orán, octubre 2014). Por estos motivos, ella organizaba actividades los fines de semana para que las personas más pequeñas de la comunidad aprendieran los ciclos de los cultivos porque, como ya hemos explicado, lxs niñxs en edad escolar no podían vivir en la comunidad.

Lxs niñxs también expresaban qué querían para su futuro. Así pues, Lucas Colque (12) me comentaba: "yo no quiero trabajar en el campo, quiero ser gendarme o policía" (Entrevista, Lucas, niño criollo, Orán, mayo 2011). Si bien Lucas no asistía a la escuelita policial, sus palabras evidenciaban el protagonismo de las instituciones de seguridad en el universo de niñxs de sectores rurales salteños. Luego de describir y analizar las condiciones laborales de lxs adultxs en este contexto, consideramos que los oficios de policía y gendarme constituían una de las pocas oportunidades para "evitar" el destino de las opciones laborales del ámbito rural: las fincas y el bagalleo. Frente a la precariedad de las condiciones laborales rurales, la labor en las fuerzas de seguridad ofrece estabilidad y supuestamente - porque sabemos que el trabajo en el Estado no siempre implica relación de dependencia - los beneficios del trabajo registrado.

De este modo, se torna posible comprender con mayor profundidad la amplia aceptación de esta institución, que contaba con más de 7000 niñxs inscriptos en el año 2014 en la provincia de Salta. ${ }^{12}$ La perspectiva etnográfica permitió observar que las actividades recreativas de los cuerpos infantiles de policía podían asemejarse a las ofertas de un club en sectores de clase media urbana.

La falta de oferta de actividades de recreación y/o esparcimiento en estos sectores sociales permitía comprender también la asistencia de niñxs a la "Escuelita Bíblica" de la "Unión de las Asambleas de Dios"13 que funcionaba en El 26 los sábados por la tarde. A dicha actividad concurrían niños de familias criollas, de origen boliviano y argentino, así como también niños de familias ava-guaraní del paraje. La primera escuelita bíblica del año, que se realizaba en marzo, resultaba un evento importante porque coincidía con el retorno de los hijos de trabajadores golondrina que viajaron a Bolivia durante la época estival. Andrés me comentaba "ahora vienen todos, pero para fin de año ya cada vez somos menos". Sus hermanos menores estaban en la primera fila con él y esperando ansiosamente que empezaran las actividades. Los "profes" eran los 
varones y las "seños" las mujeres jóvenes, que se identificaban como "misioneros" y/o "catequistas" y eran oriundos de centros urbanos del departamento. Ellxs cantaban canciones religiosas y hacían actividades recreativas para que los niños "jugando aprendan la palabra de Dios" (Registro de Campo, escuelita bíblica, Orán, marzo 2011).

La dinámica de los encuentros consistía en el armado de juegos con los niños a partir de relatos bíblicos. El énfasis en la palabra bíblica guarda relación con la particularidad de los movimientos religiosos en estos contextos, que se afirmaron fuertemente en la alfabetización, ya que su práctica se basaba en la lectura personalizada de la Biblia (Citro, 2009; Enriz, García Palacios y Hecht, 2017).

La escuelita bíblica resultaba un lugar privilegiado para contactar a madres y niños de diversas identidades. Allí no importaban las tensiones en torno a las relaciones laborales, las diversas nacionalidades o las identidades étnicas. Lxs nietxs de los abuelos ava-guaraníes corrían con lxs hijxs de criollxs, mientras las madres jornaleras bolivianas charlaban bajo una higuera. A diferencia de otros espacios, como la escuelita policial o la escuela pública, gran parte de lxs alumnxs de la escuelita bíblica concurrían con adultxs, que siempre eran mujeres: tías, abuelas y/o madres. De modo que, si bien en la escuelita bíblica confluyen múltiples identidades rurales, persiste la presencia femenina cuando hablamos de responsabilidad hacia el cuidado de los hijos. No obstante, que estas mujeres vayan a este espacio infantil, cuando sus hijxs podían hacerlo solxs, habla de que la escuelita bíblica configuraba un espacio de sociabilidad entre mujeres, ya que se quedaban durante el culto conversando entre ellas mientras lxs niñxs estaban circulando y/o siendo cuidados por otrxs.

\section{Palabras finales: el cuidado como vía para pensar la infancia}

Este artículo busca contribuir a los debates en torno a la organización social y política del cuidado infantil en el contexto argentino. Lo observado en el ámbito rural se corresponde con otros estudios realizados en ámbitos urbanos y periurbanos (Zibecchi, 2013; Faur, 2014), donde la responsabilidad del cuidado infantil recae sobre todo en las familias y, en su interior, en las mujeres. El ideal maternalista de mujeres madres trabajando únicamente como cuidadoras del hogar y de lxs niñxs resulta un horizonte utópico que permea todas las relaciones sociales. La logística familiar desplegada para cuidar a lxs más pequeñxs - sean hijxs, nietxs y/o bisnietxs - muchas veces involucra estrategias para obtener ingresos monetarios, frente a desigualdades de género que ubican a las mujeres como empleadas de los supuestos "jefes de familia".

Si bien hemos explorado una diversidad de estrategias productivas de las mujeres, como el armado de comercios o el trabajo como cuidadoras, estas opciones siempre son más inestables que las que realizan los varones, justamente porque ellas tienen menos tiempo para dedicar al trabajo remunerado, al ser las únicas responsables del cuidado infantil. Esta distribución desigual del cuidado y de los recursos económicos está estrechamente ligada a la naturalización de la capacidad de las mujeres para cuidar. Lejos de ser una capacidad natural, "se trata de una construcción social sustentada por las relaciones patriarcales de género, que se sostienen en valoraciones culturales reproducidas por diversos mecanismos como la educación [...] las religiones y las instituciones" (Rodríguez Enríquez y Marzonetto, 2016, p. 106). En este sentido, la escuelita policial infantil permite observar cómo desde las prácticas institucionales se reactualizan sentidos dicotómicos en torno a la femineidad 
y la masculinidad. Esta construcción dicotómica entre las tareas de los niños y niñas se observa también al interior de la institución familiar, donde las niñas hacen de madre, mientras los varones desde muy pequeños deben cuidar la seguridad de su familia. El cuidado entonces posee diversos significados, que se articulan con los mandatos de género.

El análisis de las prácticas de cuidado ha constituido una vía privilegiada para observar la construcción de la infancia en este contexto. Lxs niñxs emergen como activxs participantes de las relaciones de cuidado, y son responsables de actividades diferentes según las edades y los contextos. Esto se relaciona con investigaciones realizadas en contextos similares, donde lxs más pequeñxs poseen un conocimiento competente del entorno rural (Szulc, 2015) y que pueden colaborar en las tareas domésticas y en tareas de trabajo rural (Padawer, 2010). Tal como hemos observado, 1xs niñxs concurrían solos a la escuela primaria y podían quedar a cargo de sus hermanxs si lxs adultxs no estaban. Estas prácticas han sido también señaladas por Hirsch (2008) en poblaciones ava-guaraníes de otras localidades salteñas donde, para otros habitantes de la comunidad, podían ser representadas como un cuidado de mala calidad.

La perspectiva etnográfica en estos contextos permitió conocer que las vidas infantiles no se desarrollan únicamente en el ámbito doméstico y/o escolar. Lxs niñxs crecen circulando por el espacio de las fincas, advirtiendo las desigualdades del mundo rural que atraviesa sus vidas. Conocer las condiciones laborales de las personas adultas no solo permite observar los efectos de la informalidad en la vida cotidiana, sino además comprender cuáles son los valores que definen las decisiones de cada familia en torno al cuidado infantil.

A pesar de que las familias del campo de Orán no poseen muchas opciones para "desfamiliarizar" el cuidado infantil, en las decisiones que se toman para su organización interviene lo que cada madre, padre y/o grupo familiar entiende por "adecuado" para el crecimiento y el bienestar de la cría. Así pues, entran en juego una serie de valores morales en torno a aquello que se desea para lxs niñxs, lo que debe estimularse durante la crianza (actividades, formación, espacios de socialización), qué se contrapone con aquello que se comprende como peligroso (riesgos) y qué, por lo tanto, debe evitarse para que lxs niñxs crezcan adecuadamente.

Esperamos que estas palabras constituyan un aporte para pensar las prácticas de cuidado infantil por fuera de las fronteras del hogar y de las responsabilidades familiares o, mejor dicho, femeninas. Las situaciones observadas evidencian que las condiciones laborales y habitacionales, junto con el transporte público, son resultado de políticas públicas que en la agenda pública no forman parte de las intervenciones hacia la primera infancia, pero que determinan las formas de vida de la población materno-infantil.

\section{Sobre la autora}

Becaria Postdoctoral Consejo de Investigaciones Científicas y Técnicas (CONICET). 


\section{Q Referencias bibliográficas}

" Ariza, M. (2000). Migración, familia y transnacionalidad en el contexto de la globalización: algunos puntos de reflexión. Revista Mexicana de Sociología, 64(4), 53-84.

"Ceriani Cernadas, C. (2011). La misión pentecostal escandinava en el Chaco argentino: Etapa formativa: 1914-1945. Memoria Americana, 19(1), 89-115. Recuperado de http:// www.scielo.org.ar/scielo.php?script=sci_arttext\&pid=S1851-37512011000100005\&lng=e s\&tlng=es

" Cerrutti, M. S., \& Maguid, A. (2010). Familias divididas y cadenas globales de cuidado. Cepal.

"Citro, S. (2009). Cuerpos significantes: travesías de una etnografía dialéctica. Buenos Aires: Biblos.

"Colangelo, M. A. (2004). En busca de una "infancia sana": la construcción médica del niño y del cuerpo infantil. En VII Congreso Argentino de Antropología Social. Villa Giardino, Córdoba.

" Comunidad Indígena Ava-Guaraní Tabacal La Loma (CIGET) y Etchegorry, C., et al. (2013). El grito ancestral. Sapucay mate. Córdoba: Editorial Universitaria Católica de Córdoba.

"Connell, R. (1995). Masculinities. Power and Social Change. Berkeley: University of California Press.

»Egan, J. F. (2013). Del Estatuto del Peón al Régimen de Trabajo Agrario: avances y retrocesos en la regulación del trabajo rural. En XJornadas de Sociología. Facultad de Ciencias Sociales, Universidad de Buenos Aires, Buenos Aires. Recuperado de http://cdsa.aacademica.org/ooo-038/751.pdf

»Enriz, N., García Palacios, M. y Hecht, A. C. (2017). Llevar la palabra. Un análisis de la relación entre las iglesias y la escolarización de niños indígenas tobas/qom y mbyaguaraní de Argentina. Universitas Humanística, 83, 187-212.

" Faur, E. (2014). El cuidado infantil en el siglo XX. Mujeres malabaristas en una sociedad desigual. Buenos Aires: Siglo XXI.

" Hirsch, S. (2000). Misión, Región y Nación entre los guaraníes de Argentina. Procesos de integración y de re-etnización en zonas de frontera. Fronteras, naciones e identidades: la periferia como centro. Buenos Aires: Ciccus-La Crujía, 278-98.

" Gago, V. (2014). La razón neoliberal. Buenos Aires: Tinta limón.

" García Palacios, M. (2015). Monjas, asesinatos y apariciones: rumor y alteridad religiosa en el contexto de las experiencias formativas de los niños y niñas de un barrio Toba/ QOM de Buenos aires. Papeles de trabajo. Centro de Estudios Interdisciplinarios en Etnolingüistica y Antropología Socio-Cultural, 29, 49-64.

» Gilardon, E., Calvo, E., Duran, P., Longo, E., \& Mazza, C. (2009). Evaluación del estado nutricional de niñas, niños y embarazadas mediante antropometría. Ed. Buenos Aires: Ministerio de Salud de la Nación.

" Guber, R. (2001). La etnografía: método, campo y reflexividad. Buenos Aires: Norma.

"Hernando, A. (2008). Género y sexo. Mujeres, identidad y modernidad. Claves de razón práctica, 188, 64 .

" Hirsch, S. (2004). Ser Guaraní en el Noroeste Argentino: variables de la Construcción identitaria. Revista de Indias, 230, 67-80. 
"Hirsch, S. (2008). Maternidad, trabajo y poder: cambios generacionales en las mujeres guaraníes del norte. En S. Hirsch (coord.), Mujeres indígenas en la Argentina. Cuerpo, Trabajo y Poder (pp. 231-253). Buenos Aires: Biblos.

" James, A. y Prout, A. (1990). Constructing and reconstructing Childhood: Contemporary Issues in the Sociological Study of Childhood. Londres: The Falner Press.

» Jelin, E. (1984). Familia y unidad doméstica: mundo público y vida privada. Buenos Aires: CEDES.

» Jerez, O. y Rabey P. (2006) Ciudades de Frontera e Industria Azucarera. Cuaderno Urbano, 5, Recuperado de http://arq.unne.edu.ar/publicaciones/cuaderno_urbano/cu_5/ archivos/archivos_html/jerezrabey.htm

" Lanusse, P y Lazzari, A. (2008). Salteñidad y pueblos indígenas: continuidad y cambios en identidades y moralidades. En C. Briones (comp.), Cartografías argentinas. Políticas indigenistas y formaciones provinciales de alteridad. Buenos Aires: Geaprona. (pps.185-210).

» Leavy, M. P. (2015). Aportes desde la antropología para pensar el flagelo de la desnutrición. Horizontes Sociológicos, 3(1), 3-22.

»Leavy, P. (2017). Hacer crecer la cría. Un estudio antropológico sobre el cuidado y la nutrición infantil en contextos rurales del departamento de Orán, Salta (Tesis de Doctorado). Facultad de Filosofía y Letras, Universidad de Buenos Aires, Ciudad Autónoma de Buenos Aires, Argentina. Recuperado de http://repositorio.filo.uba.ar/handle/filodigital/9973

»Leavy, P. (2018). “La lucha por la tierra es también una lucha por la salud”: experiencias ava-guaraní en Orán, Salta. Voces en el Fénix, 72, 92-98.

» Leavy, P., Szulc, A. P. y Anzelin, I. (2018). Niñez indígena y desnutrición: análisis antropológico comparativo de la implementación de programas alimentarios en Colombia y Argentina. Cuadernos de antropología social, 48, 39-54.

» Morgade, G. (2001). Aprender a ser varón, aprender a ser mujer. Buenos Aires: Novedades Educativas.

» Nari, M. (2004). Políticas de maternidad y maternalismo político: Buenos Aires, 1890-1940. Buenos Aires: Biblos.

»Padawer, A. (2010). La protección de los derechos de la infancia mbyá-guaraní: aportes de la etnografía en la problematización de las experiencias formativas. Espaço Ameríndio, $4(2), 52$.

» Patton, M. (2009). Qualitative Evaluation and Research Methods. Londres: Sage.

» Rodríguez Enríquez, C. (2005). Economía del cuidado y política económica. Una aproximación a sus interrelaciones. Documento presentado en la Octava Reunión de la Mesa Directiva de la Conferencia Regional sobre la Mujer de América Latina y el Caribe, Comisión Económica para América Latina y el Caribe (CEPAL).

» Rodríguez Enríquez, C. y Marzonetto, G. (2016). Organización Social del Cuidado y Desigualdad: el déficit de políticas públicas de cuidado en Argentina. Perspectivas de Políticas Públicas, 4(8), 103-134.

» Rodríguez García, M. (2012). Barreras naturales. La conjunción de lo urbano y periurbano en San Ramón de la Nueva Orán: ciudad encajonada y dispersa. En A. Nemirovsky (editor), Globalización y agricultura periurbana en Argentina (pp. 55-68). Recuperado de http://www.flacso.org.ar/uploaded_files/Noticias/agriculturaperiurbana.pdf

» Szulc, A. (2006). Antropología y niñez: de la omisión a las “culturas infantiles”. En G. Wilde y P. Schamber (eds.), Cultura, comunidades y procesos contemporáneos (pp. 25-51). Buenos Aires: SB. 
"Szulc, A. (2015). La niñez mapuche. Sentidos de pertenencia en tensión. Buenos Aires: Biblos.

"Tassinari, A. (2007). Concepçoes indígenas de infancia no Brasil. Tellus, 13(7), 11-25.

"Torres Aliaga, T. y Torres Secchi, A. (2010). ¿Por qué callan si nacen llorando? Poder, accesibilidad y diferencias culturales en Salud. Iruya, 1978-2008. Formosa: Endepa.

»Zelizer, V. (2009). La negociación de la intimidad. Buenos Aires: Fondo de Cultura Económica.

》Zibecchi, C. (2013). Organizaciones comunitarias y cuidadoras: reconfiguración de responsabilidades en torno al cuidado infantil. En L. Pautassi y C. Zibecchi (coords.), Las Fronteras del Cuidado (pp. 317-353). Buenos Aires: Biblos.

\section{Otras fuentes consultadas}

" Gobierno de la Provincia de Salta (10 de abril de 2014). Inscripciones abiertas para los Cuerpos Infantiles de Policías. Recuperado de http://www.salta.gov.ar/prensa/noticias/ inscripciones-abiertas-para-los-cuerpos-infantiles-de-la-policia/29946

» Gobierno de la Provincia de Salta. (2 de octubre de 2014). La policía infantil forma hoy los valores de nuestros jóvenes del mañana. Recuperado de http://www.salta.gov.ar/ prensa/noticias/la-policia-infantil-forma-hoy-los-valores-de-nuestros-jovenes-de-maniana/34757.

» Instituto Nacional de Estadística y Censos -INDEC - (2010) Censo Nacional de Población y Hogares. Recuperado de http://www.indec.gov.ar/nivel4_default.asp?id_ tema_1=2\&id_tema_2=41\&id_tema_3=135.

" Instituto Nacional de Tecnología Industrial -INTI— (2017). Trabajo Informal, mejorar el control para incluir. Recuperado de https://www.inti.gob.ar/sabercomo/sc81/inti8.php. Consultado el 6/6/2017.

» Decreto № 2.360/90, Reglamentación de la Ley de pensiones a madres de 7 o más hijos. Boletín Oficial, 13 de noviembre de 1990. Recuperado de http://www.desarrollosocial. gob.ar/wp-content/uploads/2015/o7/Decreto-2360-1990-Reglamentacion-de-la-Ley-depensiones-a-madres-de-7-o-m--s-hijos.pdf

»Ley $\mathrm{N}^{\circ}$ 24.714. Decreto 1602/09, Asignación Universal por Hijo. Boletín Oficial, 18 de noviembre de 2009. Recuperado de https://www.anses.gob.ar/archivos/cartilla/fdb6b048049420d51903046be2cd428of44a455f.pdf.

》 Ley № 26.727, Régimen de Trabajo Agrario. Boletín Oficial, 27 de diciembre de 2011. Recuperado de https://www.bcr.com.ar/Granos\%20\%20Normativas/../Ley\%2026727.docx 
